\title{
Early Insights From a Digitally Enhanced Diabetes Self-Management Education and Support Program: Single-Arm Nonrandomized Trial
}

Folasade Wilson-Anumudu ${ }^{1}$, MPH; Ryan Quan ${ }^{1}, \mathrm{MPH}$; Cynthia Castro Sweet ${ }^{1}$, PhD; Christian Cerrada ${ }^{2}, \mathrm{PhD}$; Jessie Juusola $^{2}, \mathrm{PhD}$; Michael Turken ${ }^{1}$, MD, MPH; Carolyn Bradner Jasik ${ }^{1}$, MD

${ }^{1}$ Omada Health, Inc, San Francisco, CA, United States

${ }^{2}$ Evidation Health, Inc, San Mateo, CA, United States

\section{Corresponding Author:}

Folasade Wilson-Anumudu, MPH

Omada Health, Inc

500 Sansome Street, Suite 200

San Francisco, CA, 94111

United States

Phone: 16502696532

Email: folasade.anumudu@omadahealth.com

\section{Abstract}

Background: Translation of diabetes self-management education and support (DSMES) into a digital format can improve access, but few digital programs have demonstrated outcomes using rigorous evaluation metrics.

Objective: The aim of this study was to evaluate the impact of a digital DSMES program on hemoglobin $\mathrm{A}_{1 \mathrm{c}}\left(\mathrm{HbA}_{1 \mathrm{c}}\right)$ for people with type 2 diabetes.

Methods: A single-arm, nonrandomized trial was performed to evaluate a digital DSMES program that includes remote monitoring and lifestyle change, in addition to comprehensive diabetes education staffed by a diabetes specialist. A sample of 195 participants were recruited using an online research platform (Achievement Studies, Evidation Health Inc). The primary outcome was change in laboratory-tested $\mathrm{HbA}_{1 \mathrm{c}}$ from baseline to 4 months, and secondary outcomes included change in lipids, diabetes distress, and medication adherence.

Results: At baseline, participants had a mean $\mathrm{HbA}_{1 \mathrm{c}}$ of $8.9 \%$ (SD 1.9) and mean BMI of $37.5 \mathrm{~kg} / \mathrm{m}^{2}$ (SD 8.3). The average age was 45.1 years (SD 8.9), 70\% were women, and 67\% were White. At 4-month follow up, the $\mathrm{HbA}_{1 \mathrm{c}}$ decreased by $0.8 \%(P<.001$, $95 \% \mathrm{CI}-1.1$ to -0.5$)$ for the total population and decreased by $1.4 \%(P<.001,95 \% \mathrm{CI}-1.8$ to -0.9$)$ for those with an $\mathrm{HbA}_{1 \mathrm{c}}$ of $>9.0 \%$ at baseline. Diabetes distress and medication adherence were also significantly improved between baseline and follow up.

Conclusions: This study provides early evidence that a digitally enhanced DSMES program improves $\mathrm{HbA}_{1 \mathrm{c}}$ and disease self-management outcomes.

(JMIR Diabetes 2021;6(1):e25295) doi: $\underline{10.2196 / 25295}$

\section{KEYWORDS}

diabetes education; digital health; remote monitoring; type 2 diabetes

\section{Introduction}

\section{Background}

Over 34 million people in the United States have diabetes (9\% of the adult population), and 1 in 4 health care dollars spent in the United States is for diabetes care [1]. Among all diabetes cases, 90\%-95\% are type 2 diabetes mellitus (T2DM) [2]. A core component of diabetes management is comprehensive diabetes self-management education and support (DSMES), which is associated with improved outcomes and lower costs [3-5]. DSMES is traditionally delivered in person, either one on one or in a group setting with a certified diabetes care and education specialist (CDCES). 
DSMES is widely covered by private and public insurance, including Medicare, and is typically prescribed by a physician at diagnosis, when education gaps exist, or when the treatment plan is changed. The primary goal of DSMES is to help patients acquire the knowledge, skills, and abilities for diabetes self-care [6]. Core educational topics include disease awareness, glucose monitoring, medication adherence, nutrition support, delay of complications, and problem-solving [7].

Despite the widely accepted benefits of DSMES, access remains a challenge. Only 43 states and $57 \%$ of counties in those states have accredited DSMES programs in the United States [8]. As of 2017 , only $52 \%$ of people diagnosed with diabetes in the United States have accessed self-management support services, with rates decreasing in recent years [9]. To address the unmet need, technology-enabled platforms have emerged as a more accessible venue for DSMES delivery. There are numerous commercial products available that allow people to access DSMES programs through personal mobile devices (eg, smartphones, tablets, laptops) with a wide range of approaches $[10,11]$. Staffing varies widely from none (100\% patient-driven) to uncredentialed coaches to CDCES.

Technology-based DSMES programs have demonstrated a positive impact on hemoglobin $\mathrm{A}_{1 \mathrm{c}}\left(\mathrm{HbA}_{1 \mathrm{c}}\right)$ in academic settings with noncommercially available programs [12]. These interventions typically adhere to DSMES guidelines and include credentialed staff for program delivery. Commercially available technology-based DSMES solutions in the market are often limited by lack of accreditation, uncredentialed staff, and research results produced from less rigorous methods [13]. Although some studies have demonstrated that commercially available DSMES programs improve diabetes-related outcomes for users, the staffing, number of touchpoints, manner of delivery (asynchronous vs synchronous), and inclusion of connected devices, among other factors, vary widely among programs [14-16]. As such, more research is needed to understand best practices for digital DSMES delivery. Furthermore, methodologically rigorous research is also needed to demonstrate the parity of outcomes to in-person care [12].

\section{Objective}

The goal of this pilot study was to evaluate the impact of a digital DSMES program enhanced with deep lifestyle and behavior change support on $\mathrm{HbA}_{1 \mathrm{c}}$ for people with T2DM and elevated $\mathrm{HbA}_{1 \mathrm{c}}$. We hypothesized that the digital DSMES program would be associated with greater improvements in $\mathrm{HbA}_{1 \mathrm{c}}$ for people who were furthest away from their $\mathrm{HbA}_{1 \mathrm{c}}$ goal (baseline $\mathrm{HbA}_{1 \mathrm{c}} \geq 9.0 \%$ ) at the start of the program. We further evaluated the impact of the digital DSMES program on cardiovascular and patient-reported outcomes, as cardiovascular risk factors are a frequent comorbidity of diabetes.

\section{Methods}

\section{Participants}

We invited members of an online health community to participate in this study (Achievement, Evidation Health Inc). Achievement is a web- and mobile-based community in the
United States where members can connect their activity trackers, and fitness and health apps to the platform and, by logging activities, accumulate points that are redeemable for monetary rewards. Additionally, members self-report on various health conditions and are invited to participate in remote research opportunities as relevant studies become available. In this study, recruitment was targeted to members who had self-reported a diagnosis of T2DM. Invited members were linked to an online research study platform (Achievement Studies, Evidation Health Inc) where study eligibility was assessed using automated screener questions. Individuals who lived in the United States, were at least 18 years of age, self-reported a T2DM diagnosis, self-reported $\mathrm{HbA}_{1 \mathrm{c}}$ of $7.5 \%$ or greater, had a $\mathrm{BMI} \geq 25 \mathrm{~kg} / \mathrm{m}^{2}$ ( $\geq 23 \mathrm{~kg} / \mathrm{m}^{2}$ if they self-identified as Asian), and had access to a computer or smartphone to participate in the digital DSMES program were eligible for the study.

\section{Procedures}

If deemed eligible after completing the screener, potential participants continued in the online study platform to sign an electronic informed consent form and completed an online baseline survey, which consisted of questions about their demographics, health and diabetes history, and patient-reported outcomes. They then completed a baseline visit at a Quest Diagnostics Patient Service Center (PSC) of their choosing. The baseline visit consisted of a venous whole blood draw, physical measurements (height, weight, waist circumference), resting blood pressure, and resting heart rate. After completing the PSC visit, potential participants were instructed to set up their account on the digital DSMES program. After completion of a signed electronic informed consent form, and both the PSC visit and program account setup, individuals were considered enrolled in the study. Participants were able to reach out to research staff with questions via email or phone through the online study platform before and during the enrollment process, and could continue to reach out throughout the study.

During the study period, participants were encouraged to engage with the DSMES program. All participants were provided a cellularly connected weight scale that was linked to their program account. Participants who were advised to use monitoring devices in their diabetes self-care were provided cellularly connected blood pressure monitors and glucose meters. Participants were also able to access their own personal online study platform dashboard to complete study procedures and keep track of their progress throughout the study through the use of any web-enabled device. Approximately 4 months after enrollment, participants repeated the online survey and clinical outcome measures $\left(\mathrm{HbA}_{1 \mathrm{c}}\right.$, blood pressure). Participants received compensation for completing each study-related task such as surveys and lab visits. This study was approved by the Western Institutional Review Board (Puyallup, WA).

\section{Study Outcomes}

The primary outcome of this study was change in $\mathrm{HbA}_{1 \mathrm{c}}$ from baseline to 4 months, as well as changes in $\mathrm{HbA}_{1 \mathrm{c}}$ based on starting $\mathrm{HbA}_{1 \mathrm{c}}$ values. Secondary outcomes included changes in cardiovascular risk factors (blood pressure, total cholesterol [TC]) among those who started the study with elevated risk 
factors, in addition to changes in diabetes distress and medication adherence from baseline to 4 months.

\section{Measurements}

At baseline, participants completed an assessment at the PSC that included $13 \mathrm{~mL}$ venous whole blood specimen collection under sterile conditions by a trained phlebotomist. The nonfasting blood specimens were processed for $\mathrm{HbA}_{1 \mathrm{c}}$ and a lipids panel (TC, high- and low-density lipoprotein [HDL, LDL], and TC/HDL ratio). A trained technician collected blood pressure after a 5-minute quiet resting period with legs uncrossed using an automatic blood pressure monitor and size-adjustable cuff. Height was measured to the nearest centimeter using a calibrated stadiometer with the participant in stocking feet Weight was measured using a calibrated scale with the participant in light clothing and no shoes. Waist circumference was measured in whole units (inches) using a nonstretchable measuring tape above the first layer of clothing. BMI was calculated from weight in kilograms divided by height in meters squared. Results were sent by Quest Diagnostics and accessed by the research team via secure file transfer. Participants received copies of their results both via secure email and mail.

Participants completed an online survey of patient-reported outcomes including the Diabetes Distress Scale (DDS), a 17-item scale of different dimensions of distress and burden related to diabetes, which has been shown to have reliability and validity [17], and the Simplified Medication Adherence Questionnaire (SMAQ), a 6-item measure that categorizes respondents as adherent or nonadherent based on recent patterns of medication-taking behaviors [18].

The original protocol planned for a repeat assessment using identical methods 4 months after enrollment. However, the 4-month assessments were scheduled to begin in April of 2020, during the height of the COVID-19 pandemic [19]. People with diabetes are at high risk for severe illness from COVID-19 [20]; therefore, the study protocol was changed to eliminate the in-person visit to support participants to shelter in place. In replacement of the venipuncture blood draw, a Quest Diagnostics Qcard self-collection card was sent to each participant for collection of $\mathrm{HbA}_{1 \mathrm{c}}$ and blood lipids data. The Qcard is a self-collection card that uses the dried blood spot method, with a correlation to venipuncture $\mathrm{HbA}_{1 \mathrm{c}}$ in the range of 0.95 to 1.0 [21]. Triglycerides and LDL were not available through the Qcard and as such were removed as study outcomes. Weight at the 4-month time point was collected using a cellularly connected scale (BodyTrace Inc, Palo Alto, CA, USA) that was provided to every participant in the program. Participants who were given home blood pressure monitors (BodyTrace, Inc) in the program were asked to use them to collect the 4-month blood pressure reading. Blood pressure monitors were sent to participants who did not get the devices at the program start and were given instructions for collecting resting blood pressure at home at 4 months. The post-test self-report online survey was identical to the baseline survey.

\section{Intervention}

Omada for Diabetes is a digitally enhanced DSMES program designed to build self-management skills and support diabetes management between outpatient visits with primary care providers and specialists to ensure that users achieve their health targets (eg, $\mathrm{HbA}_{1 \mathrm{c}}$, blood pressure, cholesterol) and obtain health maintenance services (eg, screening for neuropathy and retinopathy). The program offers disease education, comprehensive lifestyle self-management support (ie, support for weight loss, dietary changes, physical activity increases), support for involvement in members' current medication regimen, and support for use of monitors or trackers for their blood sugar and blood pressure, which are often used to inform small modifications in food intake, physical activity, medication, or communication with health care providers. Participants used a technology-enabled platform with a portable interface to a variety of personal mobile devices. All participants received a cellularly connected BodyTrace weight scale, and if needed, a blood glucose monitor (3G BioTel Care, Telcare LLC, Concord, MA) was also provided. Participants were assigned to a CDCES who provided individualized coaching around the American Association of Diabetes Educators 7 self-care behaviors [22]. They were also placed in a virtual peer group including other program participants with T2DM, and could communicate with peers through a secure discussion board. As needed, the CDCES referred participants back to their primary care team for medication reviews or adjustments as their health targets and self-care goals were achieved. The program is accredited by the Association of Diabetes Care and Education Specialists [23]. The program takes a user-centered approach that encourages participants to engage at a time and frequency they choose, and with the tools and resources they find most useful, and does not have any predetermined volume or pattern that participants are expected to engage in program features.

\section{Statistical Analysis}

The study was powered to detect a clinically meaningful $0.5 \%$ reduction in the primary outcome of $\mathrm{HbA}_{1 \mathrm{c}}$. With an estimated standard deviation of 1.8 and power set to $90 \%$, the minimal sample size needed was 162 . To allow for potential $20 \%$ loss to follow up and $10 \%$ of lab $\mathrm{HbA}_{1 \mathrm{c}}$ values being below $7.5 \%$ at baseline, a total of 186 participants were planned for enrollment.

Descriptive statistics are presented to describe the demographics and baseline health status of participants. Baseline correlations using Pearson and Spearman correlation coefficients were examined to determine variables (age, gender, BMI) that could potentially confound $\mathrm{HbA}_{1 \mathrm{c}}$ outcomes. No significant correlations were detected; therefore, paired $t$ tests were used to examine baseline to post-test differences in study outcomes. Post hoc analyses were performed to examine the change in $\mathrm{HbA}_{1 \mathrm{c}}$ based on the starting $\mathrm{HbA}_{1 \mathrm{c}}$ range, with the hypothesis that those with higher blood glucose levels may receive greater benefit. Elevated blood pressure and blood lipids were not among the criteria for study inclusion and were therefore assessed as secondary outcomes of interest; we examined changes specifically among those who began the study with elevated cardiovascular risk factors. The McNemar test was performed to examine the change in the proportion of the population that was adherent to medications from baseline to post-test. Program engagement is summarized using averages 
across several metrics to reflect how participants engaged with the program over the course of the 4-month study.

We analyzed outcomes using complete case analysis for those who returned 4-month clinical and patient-reported survey data. Using multiple imputation, with an imputation of baseline values for primary and secondary outcomes for those with missing data at 4 months, we found that outcomes were similar in magnitude and statistical significance using both analytic methods. Therefore, we present our findings on the sample using results from the complete case analysis.

\section{Results}

\section{Study Recruitment}

Although the recruitment goal was 162 participants with starting $\mathrm{HbA}_{1 \mathrm{c}}$ above $7.5 \%, 32$ of the first 100 participants' laboratory $\mathrm{HbA}_{1 \mathrm{c}}$ result was below the $7.5 \%$ threshold. Therefore, we changed the protocol to use the baseline $\mathrm{HbA}_{1 \mathrm{c}}$ as a clinical criterion for the study and only accepted those with a lab $\mathrm{HbA}_{1 \mathrm{c}}$ value of $7.5 \%$ or greater. We continued enrollment until we reached at least 162 participants with a baseline $\mathrm{HbA}_{1 \mathrm{c}}$ of $7.5 \%$ or greater and allowed the 32 participants with a baseline $\mathrm{HbA}_{1 \mathrm{c}}$ below $7.5 \%$ to remain in the study. The final enrolled sample was 195 , including 163 with a baseline $\mathrm{HbA}_{1 \mathrm{c}}$ of $7.5 \%$ or greater and 32 with a baseline $\mathrm{HbA}_{1 \mathrm{c}}$ of less than $7.5 \%$. Six participants were withdrawn from the study: 4 developed a medical condition that precluded participation and 2 requested to voluntarily withdraw. At post-test, $78.8 \%(\mathrm{n}=149)$ of the remaining 189 participants completed the home test kit; 8 were not sent kits as they resided in states where the home test is not authorized for distribution, and $88.4 \% \quad(n=167)$ completed the online questionnaire. Study completion was defined as a final $\mathrm{HbA}_{1 \mathrm{c}}$ value or completion of the final online questionnaire. We compared baseline demographic and clinical values for participants who completed the 4-month data collection and those who were lost to follow up, and found no significant differences across any baseline characteristics. We define loss to follow up as incompletion of the primary outcome of $\mathrm{HbA}_{1 \mathrm{c}}$. See Figure 1 for the flow of participants through each stage of the study.

Figure 1. Study participant flowchart. $\mathrm{HbA}_{1 \mathrm{c}}$ : hemoglobin $\mathrm{A}_{1 \mathrm{c}}$.

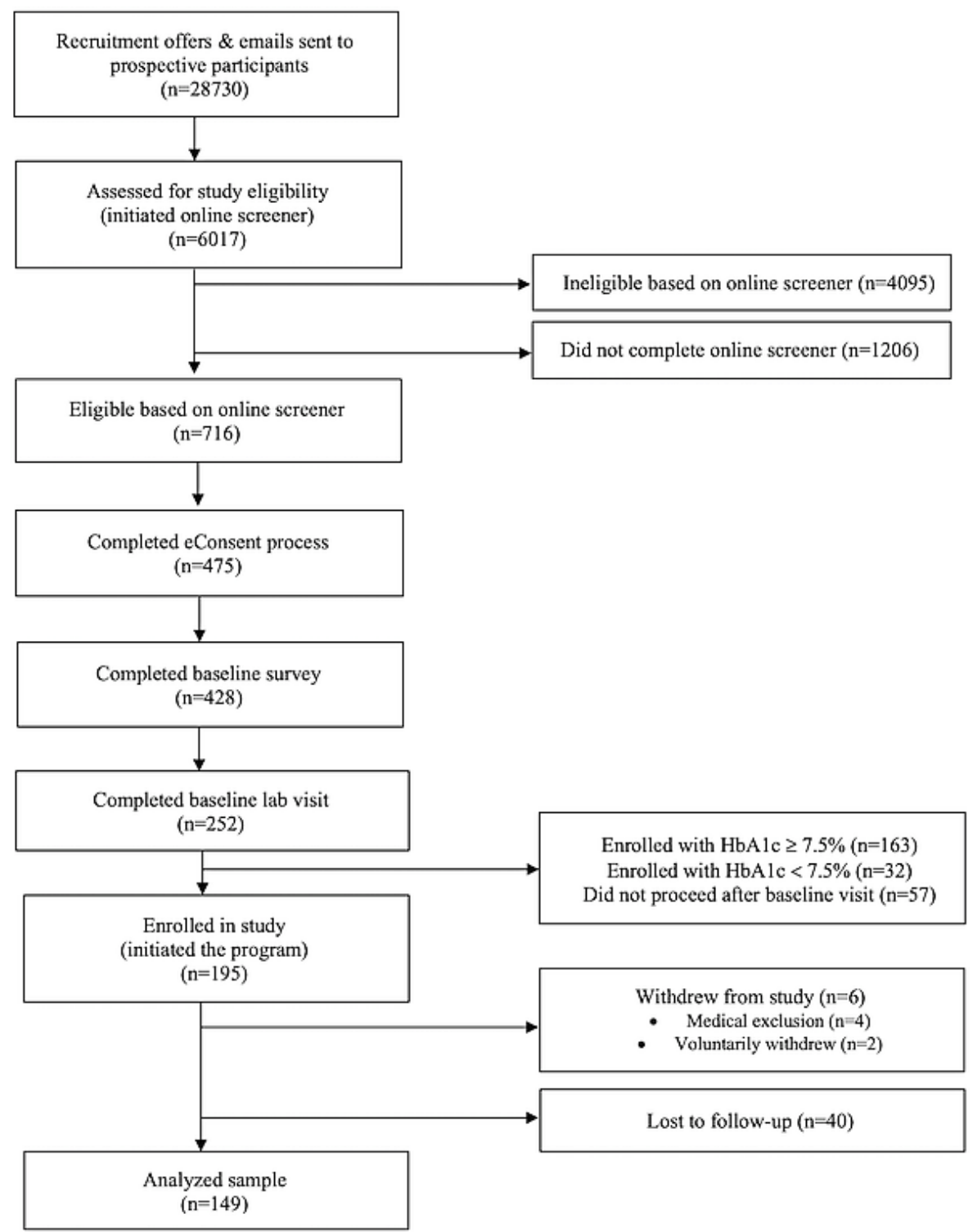




\section{Participant Characteristics at Baseline}

Baseline characteristics of participants are shown in Table 1. The average starting $\mathrm{HbA}_{1 \mathrm{c}}$ was $8.9 \%$; $50 \%$ began the study with an $\mathrm{HbA}_{1 \mathrm{c}}$ of $9.0 \%$ or higher. The mean age was 45.1 years, and the majority of participants were female and White. On average, total cholesterol was in the normal range, and blood pressure was close to the nationally recommended goal for those with diabetes. As measured by the SMAQ, 19\% of participants were adherent to their current medication regimen. The mean DDS score at baseline was 2.7. A total or subscale score $>2.0$ (moderate distress) is considered clinically meaningful; average scores <2.0 reflect little or no distress, between 2.0 and 2.9 reflect moderate distress, and $\geq 3.0$ reflect high distress [24].

Table 1. Baseline participant characteristics ( $\mathrm{N}=195)$.

\begin{tabular}{|c|c|}
\hline Baseline characteristic $^{\mathrm{a}}$ & Value \\
\hline Age (years), mean (SD) & $45.1(8.9)$ \\
\hline Female, n (\%) & $136(69.7)$ \\
\hline \multicolumn{2}{|l|}{ Race/ethnicity, n (\%) } \\
\hline White/Caucasian & $131(67.2)$ \\
\hline Black/African American & $32(16.4)$ \\
\hline Hispanic or Latino & $17(8.7)$ \\
\hline Asian & $6(3.1)$ \\
\hline American Indian or Alaska Native & $2(1.0)$ \\
\hline Native Hawaiian or other Pacific Islander & $1(0.5)$ \\
\hline Other & $6(3.1)$ \\
\hline BMI, mean (SD) & $37.5(8.3)$ \\
\hline Weight (pounds), mean (SD) & $235.6(57.3)$ \\
\hline Weight (kg), mean (SD) & $106.9(26.0)$ \\
\hline Hemoglobin $\mathrm{A}_{1 \mathrm{c}}$, mean (SD) & $8.9(1.9)$ \\
\hline Total cholesterol (mg/dL), mean (SD) & $178.9(43.3)$ \\
\hline Systolic blood pressure (mmHg), mean (SD) & $127.0(16.1)$ \\
\hline Diastolic blood pressure (mmHg), mean (SD) & $82.0(10.4)$ \\
\hline Diabetes Distress Score, mean (SD) & $2.7(1.0)$ \\
\hline Adherent to current medications, $\mathrm{n}(\%)$ & $36(18.5)$ \\
\hline
\end{tabular}

${ }^{a}$ There were no statistically significant differences across baseline characteristics among those with and without follow-up data.

\section{Program Engagement}

Averaged across the 16 program weeks, participants used their blood glucose meter an average of 7.4 times per week. Participants weighed in an average of 4.9 times per week, interacted with their CDCES an average of 1.6 times per week, completed an average of 0.8 lessons per week, interacted with their peer groups an average of 0.9 times per week, tracked their physical activity 5.3 times per week, and tracked meals an average of 10.2 times per week.

\section{Diabetes Outcomes}

Baseline to post-test changes in all study outcomes are shown in Table 2. Among all participants who completed both a baseline and 4-month $\mathrm{HbA}_{1 \mathrm{c}}$ test ( $\left.\mathrm{n}=149\right)$, participants achieved a statistically significant decrease in $\mathrm{HbA}_{1 \mathrm{c}}$ of $0.8 \%\left(t_{148}=-6.2\right.$, $P<.001)$. Table 3 shows changes based on starting $\mathrm{HbA}_{1 \mathrm{c}}$ values. Those who started the study with an $\mathrm{HbA}_{1 \mathrm{c}}$ of $9.0 \%$ or higher saw the greatest magnitude of change, with an average decrease of $1.4 \%\left(t_{72}=-6.1, P<.001\right)$. Across the total sample, weight significantly decreased an average of 3.0 pounds over 4 months $\left(t_{146}=-2.2, P=.03\right)$, and $18.4 \%$ of the sample achieved significant weight loss (>5\% body weight) (Table 2 ). 
Table 2. Baseline to post-test changes in clinical outcomes $(\mathrm{N}=167)$.

\begin{tabular}{|c|c|c|c|c|c|c|}
\hline Outcomes & $\mathrm{n}$ & Baseline & Post-test & Difference & $95 \% \mathrm{CI}$ & $P$ value \\
\hline \multicolumn{7}{|l|}{ Total sample ${ }^{\mathbf{a}}$} \\
\hline $\mathrm{HbA}_{1 \mathrm{c}}{ }^{\mathrm{b}}(\%)$ & 149 & 8.9 & 8.1 & -0.8 & -1.1 to -0.5 & $<.001$ \\
\hline Weight (pounds) & 147 & 231.4 & 228.3 & -3.0 & -5.8 to -0.3 & .03 \\
\hline Weight (kg) & 147 & 105.0 & 103.6 & -1.4 & -2.6 to -0.1 & .03 \\
\hline $5 \%$ weight loss $(\%)$ & 147 & 0.0 & 18.4 & 18.4 & 0.1 to 0.2 & $<.001$ \\
\hline Diabetes Distress Scale & 167 & 2.6 & 2.3 & -0.3 & -0.5 to -0.2 & $<.001$ \\
\hline Emotional Burden & 167 & 2.7 & 2.4 & -0.3 & -0.5 to -0.1 & $<.001$ \\
\hline Physician-Related & 167 & 2.1 & 1.8 & -0.3 & -0.4 to -0.1 & .001 \\
\hline Regimen-Related & 167 & 3.0 & 2.6 & -0.4 & -0.6 to -0.3 & $<.001$ \\
\hline Interpersonal & 167 & 2.7 & 2.4 & -0.3 & -0.5 to -0.1 & .002 \\
\hline Medication adherence (\%) & 158 & 20.3 & 31.0 & 10.7 & ${ }^{\mathrm{c}}$ & .01 \\
\hline \multicolumn{7}{|l|}{ Elevated risk subsample ${ }^{d}$} \\
\hline $\mathrm{TC}^{\mathrm{e}}(\mathrm{mg} / \mathrm{dL})$ & 43 & 230.0 & 190.5 & -39.5 & -51.3 to -27.6 & $<.001$ \\
\hline $\mathrm{SBP}^{\mathrm{f}}(\mathrm{mmHg})$ & 114 & 131.6 & 132.5 & 0.9 & -2.1 to 3.9 & .54 \\
\hline $\mathrm{DBP}^{\mathrm{g}}(\mathrm{mmHg})$ & 114 & 84.7 & 82.0 & -2.7 & -4.3 to -1.0 & .002 \\
\hline
\end{tabular}

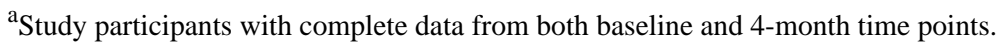

${ }^{\mathrm{b}} \mathrm{HbA}_{1 \mathrm{c}}$ : hemoglobin $\mathrm{A}_{1 \mathrm{c}}$.

c_: Not applicable.

${ }^{\mathrm{d}}$ Study participants who began the study with elevated cardiovascular risk factors.

e TC: total cholesterol.

${ }^{\text {f }}$ SBP: systolic blood pressure.

${ }^{\mathrm{g}}$ DBP: diastolic blood pressure.

Table 3. Baseline to post-test changes in hemoglobin $A_{1 c}\left(H_{b A}\right)$ based on starting $\mathrm{HbA}_{1 c}$.

\begin{tabular}{|c|c|c|c|c|c|c|}
\hline $\mathrm{HbA}_{1 \mathrm{c}}$ category & $\mathrm{n}$ & Baseline & Post-test & Difference & $95 \% \mathrm{CI}$ & $P$ value \\
\hline$<7.5 \%$ & 24 & 6.3 & 6.4 & 0.1 & -0.2 to 0.4 & .49 \\
\hline $7.5 \%-7.9 \%$ & 24 & 7.7 & 7.4 & -0.3 & -0.6 to 0.1 & .18 \\
\hline $8.0 \%-8.9 \%$ & 28 & 8.4 & 7.8 & -0.6 & -1.0 to -0.2 & .002 \\
\hline$>9.0 \%$ & 73 & 10.4 & 9.0 & -1.4 & -1.8 to -0.9 & $<.001$ \\
\hline
\end{tabular}

\section{Cardiovascular Outcomes}

At baseline, 58.5\% (114/195) of the participants had systolic or diastolic blood pressure above the normal range $(<120 \mathrm{mmHg}$ and $<80 \mathrm{mmHg}$, respectively). There was no significant change in systolic blood pressure, whereas diastolic blood pressure decreased by an average of $2.7 \mathrm{mmHg}\left(t_{113}=-3.2, P=.002\right)$. Only 43 participants had elevated TC above $200 \mathrm{mg} / \mathrm{dL}$ at baseline, and a significant decrease was found post-test $\left(t_{42}=-6.7, P<.001\right)$ (Table 2).

\section{Patient-Reported Outcomes}

In the total sample, diabetes distress significantly decreased from 2.6 at baseline to 2.3 at post-test $\left(t_{166}=4.5, P<.001\right.$; Table 2). Significant improvements in distress were observed across all DDS subscales $(P<.01)$. The proportion of the sample adherent to their medication regimen increased from $20 \%$ at baseline to $31 \%$ at post-test (McNemar $\chi_{1,158}^{2}=7.0, P=.01$ ).

\section{Discussion}

\section{Principal Findings}

The results of this study provide initial evidence that the enhanced digital DSMES program was effective for improving HbAlc, weight, diabetes distress, and medication adherence among a sample of people with T2DM and elevated $\mathrm{HbA}_{1 \mathrm{c}}$. Furthermore, those who were furthest from their $\mathrm{HbA}_{1 \mathrm{c}}$ goal at the start of the program (baseline $\mathrm{HbA}_{1 \mathrm{c}} \geq 9.0 \%$ ) achieved the greatest improvement in $\mathrm{HbA}_{1 \mathrm{c}}$, with an average change of $1.4 \%$. 
We found an inconsistent impact on cardiovascular outcomes among participants who started the study with elevated risk factors, with some improvements in diastolic blood pressure and $\mathrm{TC}$, but no improvements in systolic blood pressure. However, blood pressure at baseline was close to the nationally recommended goal for those with diabetes, and the program was not designed to address hypertension specifically. Engagement was strong as evidenced by the high frequency of use across the features of the digital platform.

These results are consistent with prior studies of digital DSMES programs (both academic and commercial) that showed improvements in $\mathrm{HbA}_{1 \mathrm{c}}$ and psychosocial outcomes [3,25-28]. In particular, the magnitude of the $\mathrm{HbA}_{1 \mathrm{c}}$ reduction in this program is comparable to that of prior studies. Kumar et al [15] reported an $\mathrm{HbA}_{1 \mathrm{c}}$ reduction of $0.86 \%$ and a higher effect in those with a higher baseline $\mathrm{HbA}_{1 \mathrm{c}}$. Dixon et al [16] reported a higher reduction in $\mathrm{HbA}_{1 \mathrm{c}}$ by baseline group, but the intervention also included medication titration and physician support. This study adds to the growing evidence that digital DSMES significantly improves $\mathrm{HbA}_{1 \mathrm{c}}$, and can also impact weight loss and cholesterol [12,29].

The clinical outcomes observed in this study meet or exceed those expected from traditional DSMES programs as set by the American Diabetes Association [30], as well as more resource-intensive digitally delivered programs that combine DSMES with physician telehealth services [16]. Further, the high rates of participant engagement with the program highlight many of the benefits of continuously accessible DSMES.

The improvements in medication adherence are encouraging given that this is a major challenge in diabetes management [31-33]. Digital delivery offers unique opportunities for patient engagement around improving medication-taking behaviors, as CDCES staff can be more proactive and support medication use in a timelier manner. Mobile apps can surface more frequent screenings, follow up, and in-app tracking to identify issues sooner so that a CDCES can reach out and provide education and support.

\section{Limitations}

There were several limitations to this pilot study. First, this pilot study is limited by its single-arm design and therefore carries the typical challenges in a nonrandomized design of unknown causal inference. Future research will benefit from a control group comparison and a randomized design to allow for a maximally rigorous test of the intervention. Second, we had to change the study methodology for follow-up lab measurement due to COVID-19 by shifting to a self-collected blood specimen versus a phlebotomist-collected venipuncture specimen; this creates potential for measurement error between instruments. However, this risk is attenuated by the high correlation of the venipuncture $\mathrm{HbA}_{1 \mathrm{c}}$ and dried blood spot method [21]. Third, it is possible that the study sample recruited may not be fully representative or generalizable of the population of people living with diabetes, as participants self-selected from the online health community into the research opportunity. However, the clinical criteria (ie, $\mathrm{HbA}_{1 \mathrm{c}}$ outside of the desired therapeutic range) increases the likelihood that study participants were individuals who would benefit from better diabetes self-management. Despite the high rates of program engagement observed among participants across the 4-month study, expectations around engagement in digital health studies remain exploratory, with varying definitions of meaningful engagement across digital platforms.

\section{Conclusions}

This study provides additional evidence that a digitally delivered DSMES program enhanced with deep lifestyle and behavior change support impacts $\mathrm{HbA}_{1 \mathrm{c}}$ for people with $\mathrm{T} 2 \mathrm{DM}$ and elevated $\mathrm{HbA}_{1 \mathrm{c}}$, showing the greatest benefit for those with higher blood glucose levels, and suggests benefits for weight loss and improvements in cardiovascular outcomes. Future research is needed to understand the potential impact of digital DSMES on long-term diabetes outcomes to meet the needs of the changing health care landscape.

\section{Acknowledgments}

The authors would like to thank Andrea Newcom, Bailey Peterka, Carolyn Salter, Danene Moberly, Melinda Merry, and Brieana Polk-Perez for their support of the project and work with participants. We would also like to thank Sara Cross and Anna Telthorst from Quest Diagnostics, and Kimberly Russell, Lisa Johnstone, Amber Hogue, and Maximo Prescott from Evidation Health for study management. Data included in this manuscript were presented in an abstract at the 20th Annual Diabetes Technology Meeting Virtual Poster Session on November 19, 2020. This study was funded by Omada Health, Inc.

\section{Conflicts of Interest}

FWA, RQ, CCS, MT, and CBJ are employees of Omada Health, Inc, and receive salary and stock options. CC and JJ are employees of Evidation Health, Inc, and receive salary. Evidation Health, Inc received funds from Omada Health, Inc to perform the study.

\section{References}

1. American Diabetes Association. Economic costs of diabetes in the U.S. in 2017. Diabetes Care 2018 May;41(5):917-928 [FREE Full text] [doi: 10.2337/dci18-0007] [Medline: 29567642]

2. National Diabetes Statistics Report, 2020. Centers for Disease Control and Prevention. URL: https://www.cdc.gov/diabetes/ pdfs/data/statistics/national-diabetes-statistics-report.pdf [accessed 2020-08-05] 
3. Chrvala CA, Sherr D, Lipman RD. Diabetes self-management education for adults with type 2 diabetes mellitus: A systematic review of the effect on glycemic control. Patient Educ Couns 2016 Jun;99(6):926-943 [FREE Full text] [doi: 10.1016/j.pec.2015.11.003] [Medline: 26658704]

4. Duncan I, Birkmeyer C, Coughlin S, Li QE, Sherr D, Boren S. Assessing the value of diabetes education. Diabetes Educ 2009;35(5):752-760. [doi: 10.1177/0145721709343609] [Medline: 19783766]

5. Strawbridge LM, Lloyd JT, Meadow A, Riley GF, Howell BL. One-year outcomes of diabetes self-management training among medicare beneficiaries newly diagnosed with diabetes. Med Care 2017 Apr;55(4):391-397. [doi: 10.1097/MLR.0000000000000653] [Medline: 27753746]

6. Beck J, Greenwood DA, Blanton L, Bollinger ST, Butcher MK, Condon JE, 2017 Standards Revision Task Force. 2017 National Standards for Diabetes Self-Management Education and Support. Diabetes Educ 2017 Oct;43(5):449-464. [doi: 10.1177/0145721717722968] [Medline: 28753378]

7. American Diabetes Association. Facilitating behavior change and well-being to improve health outcomes: standards of medical care in diabetes - 2020. Diabetes Care 2020 Jan;43(Suppl 1):S48-S65. [doi: 10.2337/dc20-S005] [Medline: $\underline{31862748]}$

8. Morgan JM, Mensa-Wilmot Y, Bowen S, Murphy M, Bonner T, Rutledge S, et al. Implementing Key Drivers for Diabetes Self-Management Education and Support Programs: Early Outcomes, Activities, Facilitators, and Barriers. Prev Chronic Dis 2018 Jan 25;15:E15 [FREE Full text] [doi: 10.5888/pcd15.170399] [Medline: 29369755]

9. Healthy People 2020. Office of Disease Prevention and Health Promotion. URL: https://www.healthypeople.gov/2020/ data/Chart/4111?category $=1 \&$ by $=$ Total \& fips $=0$ [accessed 2020-08-04]

10. Thangada ND, Garg N, Pandey A, Kumar N. The emerging role of mobile-health applications in the management of hypertension. Curr Cardiol Rep 2018 Jul 26;20(9):78. [doi: 10.1007/s11886-018-1022-7] [Medline: 30046971]

11. Veazie S, Winchell K, Gilbert J, Payntner R, Ivlev I, Eden K, et al. Mobile applications for self-management of diabetes: Technical Brief, No. 31. Rockville, MA: US Agency for Healthcare Research and Quality; 2018. URL: https://www. ncbi.nlm.nih.gov/books/NBK518944/ [accessed 2021-02-15]

12. Greenwood DA, Gee PM, Fatkin KJ, Peeples M. A Systematic Review of Reviews Evaluating Technology-Enabled Diabetes Self-Management Education and Support. J Diabetes Sci Technol 2017 Sep;11(5):1015-1027 [FREE Full text] [doi: 10.1177/1932296817713506] [Medline: 28560898]

13. Levine BJ, Close KL, Gabbay RA. A care team-based classification and population management schema for connected diabetes care. NPJ Digit Med 2020 Aug 07;3(1):104. [doi: 10.1038/s41746-020-00313-3] [Medline: 32802969]

14. Bollyky JB, Bravata D, Yang J, Williamson M, Schneider J. Remote lifestyle coaching plus a connected glucose meter with certified diabetes educator support improves glucose and weight loss for people with type 2 diabetes. J Diabetes Res 2018;2018:3961730. [doi: 10.1155/2018/3961730] [Medline: 29888288]

15. Kumar S, Moseson H, Uppal J, Juusola JL. A diabetes mobile app with in-app coaching from a certified diabetes educator reduces A1C for individuals with type 2 diabetes. Diabetes Educ 2018 Jun;44(3):226-236. [doi: 10.1177/0145721718765650] [Medline: 29575982]

16. Dixon RF, Zisser H, Layne JE, Barleen NA, Miller DP, Moloney DP, et al. A virtual type 2 diabetes clinic using continuous glucose monitoring and endocrinology visits. J Diabetes Sci Technol 2020 Sep;14(5):908-911 [FREE Full text] [doi: 10.1177/1932296819888662] [Medline: $\underline{31762302}$ ]

17. Polonsky WH, Fisher L, Earles J, Dudl RJ, Lees J, Mullan J, et al. Assessing psychosocial distress in diabetes: development of the diabetes distress scale. Diabetes Care 2005 Mar;28(3):626-631. [doi: 10.2337/diacare.28.3.626] [Medline: 15735199]

18. Knobel H, Alonso J, Casado JL, Collazos J, González J, Ruiz I, GEEMA Study Group. Validation of a simplified medication adherence questionnaire in a large cohort of HIV-infected patients: the GEEMA Study. AIDS 2002 Mar 08;16(4):605-613. [doi: 10.1097/00002030-200203080-00012] [Medline: 11873004]

19. Listing of WHO's response to COVID-19. World Health Organization. URL: https://www.who.int/news-room/detail/ 29-06-2020-covidtimeline [accessed 2020-08-07]

20. Certain medical conditions and risk for severe COVID-19 illness. Centers for Disease Control and Prevention. URL: https:/ /www.cdc.gov/coronavirus/2019-ncov/need-extra-precautions/people-with-medical-conditions.html [accessed 2020-12-15]

21. Biometric wellness screening modality comparison. Quest Diagnostics. URL: https://www.questforhealth.com/wp-content/ uploads/dlm_uploads/2017/01/Veni-FingerStk-Qcard-comparison_4-23-18-1.pdf [accessed 2020-08-09]

22. American Association of Diabetes Educators. In: Cornell S, Halstenson C, Miller DK, editors. The art and science of diabetes self-management education desk reference, 4th Edition. Chicago, IL: AADE; 2017.

23. Beck J, Greenwood DA, Blanton L, Bollinger ST, Butcher MK, Condon JE, 2017 Standards Revision Task Force. 2017 National Standards for Diabetes Self-Management Education and Support. Diabetes Educ 2018 Feb;44(1):35-50. [doi: 10.1177/0145721718754797] [Medline: 29346744]

24. Fisher L, Hessler DM, Polonsky WH, Mullan J. When is diabetes distress clinically meaningful?: establishing cut points for the Diabetes Distress Scale. Diabetes Care 2012 Feb;35(2):259-264 [FREE Full text] [doi: 10.2337/dc11-1572] [Medline: 22228744]

25. Powers MA, Bardsley J, Cypress M, Duker P, Funnell MM, Hess Fischl A, et al. Diabetes self-management education and support in type 2 diabetes: A joint position statement of the American Diabetes Association, the American Association of 
Diabetes Educators, and the Academy of Nutrition and Dietetics. Diabetes Care 2015 Jul;38(7):1372-1382. [doi: 10.2337/dc15-0730] [Medline: 26048904]

26. Nicolucci A, Cavaliere D, Scorpiglione N, Carinci F, Capani F, Tognoni G, et al. A comprehensive assessment of the avoidability of long-term complications of diabetes. A case-control study. SID-AMD Italian Study Group for the Implementation of the St. Vincent Declaration. Diabetes Care 1996 Sep;19(9):927-933. [doi: 10.2337/diacare.19.9.927] [Medline: $\underline{8875084}$ ]

27. Cochran J, Conn VS. Meta-analysis of quality of life outcomes following diabetes self-management training. Diabetes Educ 2008;34(5):815-823 [FREE Full text] [doi: 10.1177/0145721708323640] [Medline: $\underline{18832286}$ ]

28. Duncan I, Ahmed T, Li QE, Stetson B, Ruggiero L, Burton K, et al. Assessing the value of the diabetes educator. Diabetes Educ 2011;37(5):638-657. [doi: 10.1177/0145721711416256] [Medline: 21878591]

29. Pereira K, Phillips B, Johnson C, Vorderstrasse A. Internet delivered diabetes self-management education: a review. Diabetes Technol Ther 2015 Jan;17(1):55-63. [doi: 10.1089/dia.2014.0155] [Medline: 25238257]

30. American Diabetes Association. 6. Glycemic Targets: Standards of Medical Care in Diabetes 2020. Diabetes Care 2020 Jan;43(Suppl 1):S66-S76. [doi: 10.2337/dc20-S006] [Medline: 31862749]

31. Fischer MA, Stedman MR, Lii J, Vogeli C, Shrank WH, Brookhart MA, et al. Primary medication non-adherence: analysis of 195,930 electronic prescriptions. J Gen Intern Med 2010 Apr;25(4):284-290 [FREE Full text] [doi: 10.1007/s11606-010-1253-9] [Medline: 20131023]

32. Giugliano D, Maiorino MI, Bellastella G, Esposito K. Clinical inertia, reverse clinical inertia, and medication non-adherence in type 2 diabetes. J Endocrinol Invest 2019 May;42(5):495-503. [doi: 10.1007/s40618-018-0951-8] [Medline: 30291589]

33. Polonsky WH, Henry RR. Poor medication adherence in type 2 diabetes: recognizing the scope of the problem and its key contributors. Patient Prefer Adherence 2016;10:1299-1307 [FREE Full text] [doi: 10.2147/PPA.S106821] [Medline: 27524885]

\author{
Abbreviations \\ CDCES: certified diabetes care and education specialist \\ DDS: Diabetes Distress Scale \\ DSMES: diabetes self-management education and support \\ $\mathbf{H b A}_{1 \mathbf{c}}$ : hemoglobin $\mathrm{A}_{1 \mathrm{c}}$ \\ HDL: high-density lipoprotein \\ LDL: low-density lipoprotein \\ PSC: Patient Service Center \\ SMAQ: Simplified Medication Adherence Questionnaire \\ T2DM: type 2 diabetes mellitus \\ TC: total cholesterol
}

Edited by C Richardson; submitted 27.10.20; peer-reviewed by A Hughes, J Layne, S Schembre; comments to author 19.11.20; revised
version received 12.01.21; accepted 20.01.21; published 22.02.21
Please cite as:
Wilson-Anumudu F, Quan R, Castro Sweet C, Cerrada C, Juusola J, Turken M, Bradner Jasik C
Early Insights From a Digitally Enhanced Diabetes Self-Management Education and Support Program: Single-Arm Nonrandomized
Trial
JMIR Diabetes $2021 ; 6(1):$ e25295
URL: $\underline{\text { https://diabetes.jmir.org/2021/1/e25295 }}$
doi: $\underline{10.2196 / 25295}$
PMID: $\underline{33616533}$

CFolasade Wilson-Anumudu, Ryan Quan, Cynthia Castro Sweet, Christian Cerrada, Jessie Juusola, Michael Turken, Carolyn Bradner Jasik. Originally published in JMIR Diabetes (http://diabetes.jmir.org), 22.02.2021. This is an open-access article distributed under the terms of the Creative Commons Attribution License (https://creativecommons.org/licenses/by/4.0/), which permits unrestricted use, distribution, and reproduction in any medium, provided the original work, first published in JMIR Diabetes, is properly cited. The complete bibliographic information, a link to the original publication on http://diabetes.jmir.org/, as well as this copyright and license information must be included. 